\title{
Sistem Pengendalian Manajemen Pelayanan Kesehatan Di Unit Pengobatan Penyakit Paru-Paru (UP4) Provinsi Kalimantan Barat
}

\author{
Juliyanti Pasorong*, Antono Suryo Putro**, M. Sakundarno Adi** \\ *UP4 Kalimantan Barat, \\ ** Fakultas Kesehatan Masyarakat, Universitas Diponegoro \\ Email: pasorongjuliyanti@gmail.com
}

\section{ABSCTRACT:}

The performance of UP4 in West Borneo Province in providing health services to the public depends on the management successfulness in implementing the management control systems (MCS) as a management tool to achieve organizational goals. Therefore it is necessary to analyze the implementation of MCS in UP4 in support of UP4 efforts and performance to provide health services to the public. This research design using qualitative descriptive approach. Data collection in this research using interview, observation, and document review method. The main informant in this research is the management consisting the head office of UP4 and head of department, while the triangulation informant is the employees in each department or section. Data Processing and analysisin this research using Content analysis techniques. The results show that each dimention of MCS in UP4 such as planning system, operational system, performance measurement system, feedback system, and evaluation and reward doesn't implemented properly. In each MCS form such as planning, operational systems, feedback systems there are still problems encountered in the implementation which resulted in the MCS being less effective. This study found that the aspect of participation and communication became the main problem in the implementation of MCS. UP4 also doesn't have a well-formulated performance measurement system and evaluation and reward system. It is recommended that UP4 can increase employee participation in planning activities, increase formal and informal discussions to bridge frequent miscommunications, as well as to design a better performance measurement systems and evaluation and reward systems.

Keywords: MCS, UP4 Performance, Health Service Quality

\section{PENDAHULUAN}

Upaya untuk meningkatkan kinerja dalam meningkatkan kualitas kesehatan masyarakat dilakukan pemerintah daerah dengan perbaikan secara terus-menerus (continous improvement) baik dalam bidang administrasi, pelayanan, teknologi kesehatan dan sebagainya. Pembangunan kesehatan merupakan salah satu bidang pelayanan umum yang wajib dilaksanakan oleh pemerintah daerah (provinsi) dan bertanggungjawab sepenuhnya dalam penyelenggaraan pembangunan kesehatan dalam meningkatkan taraf kesehatan masyarakat. ${ }^{1,2}$

Di Provinsi Kalimantan Barat, pemerintah daerah membentuk Unit Pengobatan Penyakit Paru-Paru (UP4) yang 
merupakan unit khusus dibawah Dinas Kesehatan Provinsi Kalimantan Barat sebagai salah satu wujud upaya pemerintah dalam proses pembangunan kesehatan masyarakat berkaitan dengan pengobatan penyakit TB Paru.

Keberhasilan UP4 dalam mencapai tujuan organisasi dalam memberikan pelayanan kesehatan yang berkualitas terhadap masyarakat sangat berkaitan erat dengan usaha seluruh anggota organisasi untuk mencapai kinerja yang tinggi. Dalam upaya untuk memenuhi kebutuhan pencapaian tujuan organisasi, maka organisasi harus bisa melakukan pengendalian terhadap perilaku dari anggota organisasi. ${ }^{3}$ Oleh karena itu, untuk membantu mengendalikan seluruh perilaku dari anggota organisasi, maka organisasi perlu untuk mengkombinasikan teknikteknik seperti anggaran, aturan, standard operating procedures (SOP), deskripsi pekerjaan, pengukuran dan penilaian kinerja, dimana teknik-teknik ini merupakan bagian dari sebuah sistem yang nyata yang disebut sebagai sistem pengendalian manajemen (SPM). ${ }^{3}$ Hal ini menunjuukan bahwa keberhasilan UP4 dalam memberikan pelayanan kesehatan terhadap masyarakat sangat berkaitan erat penerapan SPM.

SPM di dalam lingkungan organisasi pemerintah seperti UP4, merupakan sistem yang didesain untuk melakukan pengendalian terhadap kinerja organisasi. SPM adalah proses yang integral pada tindakan dan kegiatan yang dilakukan secara terus menerus oleh pimpinan dan seluruh pegawai untuk memberikan keyakinan memadai atas tercapainya tujuan organisasi melalui kegiatan yang efektif dan efisien, keandalan pelaporan keuangan, pengamanan aset negara, dan ketaatan terhadap peraturan perundang-undangan. ${ }^{4}$

SPM organisasi pemerintah pada umumnya terdiri atas beberapa bentuk sistem pengendalian yaitu sistem perumusan strategi, sistem perencanaan, sistem penyusunan program, sistem penyusunan anggran, sistem pengukuran dan penilaian kinerja, dan sistem pemantauan. ${ }^{5}$ Komponen-komponen SPM ini bekerja sebagai suatu kesatuan yang terintegrasi dalam organisasi untuk membantu organisasi dalam mencapai tujuannya.

SPM yang diterapkan oleh UP4 digunakan untuk mengelola, mengatur serta memotivasi seluruh anggota UP4 agar bekerja sesuai dengan strategi organisasi dalam rangka mencapai tujuan untuk memberikan pelayanan kesehatan yang berkualitas bagi masyarakat. Pda prinsipnya SPM digunakan sebagai alat manajemen sebagai usaha untuk meningkakan probabilitas bahwa anggota organisasi akan berjalan sesuai cara yang akan mengarahkan pada pencapaian tujuan organisasi. $^{6}$

Laporan Kinerja Tahunan Pemerintah (LKTP) UP4 tahun 2015, menunjukkan bahwa walaupun UP4 telah melaksanakan program-program kerjanya tetapi pelayanan kesehatan yang berkualitas belum mampu dicapai secara baik. Data menunujukkan bahwa persentase penderita TB Paru BTA positif diantara semua penderita TB Paru tercatat menunjukkan angka $54,23 \%$ yang kurang dari nilai standar (65\%), dimana angka lebih rendah ini menandakan mutu diagnosis rendah dan kurang memberikan prioritas untuk menemukan pasien yang menular (pasien BTA Positif). ${ }^{7}$ Hal ini terjadi di UP4 disebabkan oleh karena kurang informasi kepada masyarakat untuk berobat ke UP4. ${ }^{7}$ Data jumlah pasien yang diobati di UP4 Provinsi Kalimantan Barat pada tahun 2015 adalah sebanyak 40 (empat puluh ) Pasien penyakit TB paru, dimana tipe penderita lebih besar adalah pasien baru. Hal ini bisa menunjukkan kemungkinan jumlah pasien TB paru di Provinsi Kalimantan Barat kian bertambah. ${ }^{7}$ Pertambahan jumlah penderita TB paru menjadi indikasai bahwa pelayanan kesehatan yang diberikan belum maksimal. UP4 juga diperhadapkan dengan permasalahan seperti kurangnya distribusi informasi dan belum memadainya tatalaksana kasus. 
Masalah-masalah ini memiliki keterkaitan dengan pelaksanaan SPM karena maksimal atau tidaknya kinerja UP4 dalam memberikan pelayanan kesehatan sangat bergantung pada penerapan SPM sebagai alat manajemen untuk mencapai tujuan organisasi. SPM yang terdiri dari berbagai bentuk pengendalian manajemen jika didesain dan diterapkan secara baik akan dapat mengendaliakan dan memotivasi setiap individu untuk berperilaku sesuai dengan yang diharapkan pihak UP4 yang pada akhirnya menuju pada pencapaian tujuan organisasi untuk memberikan pelayanan kesehatan yang berkualitas.

Penelitian-penelitian terdahulu telah menganalisis kualitas pelayanan kesehatan berdasarkan pada persepsi pasien (pelanggan) tanpa mempertimbangkan elemen organisasional seperti SPM sebagai faktor yang penting dalam mendukung terciptanya pelayanan kesehatan yang berkualitas. ${ }^{8-12}$

Sehingga penelitian ini bermaksud untuk menganalisis pelaksanaan sistem pengendalian manajemen (SPM) di UP4 sebagai alat manajemen dalam meningkatkan kualitas pelayanan kesehatan.

\section{METODE PENELITIAN}

Peneliti menggunakan pendekatan kualitatif karena melalui pendekatan ini peneliti dapat memahami mengenai kasus yang dialami oleh informan secara mendalam. Penelitian ini menggunakan metode Observasi, wawancara mendalam, dan dokumentasi untuk mengumpulkan data yang komprehensif. ${ }^{13}$ Informan dalam penelitian ini berjumlah 6 (enam) orang yang terdiri dari (a) informan utama yang terdiri dari 3 orang dari pihak manajemen; dan (b) informan triangulasi yang terdiri dari 3 orang dari pihak pegawai. Kriteria yang digunakan dalam penelitian ini untuk memilih informan/partisipan dalam penelitian ini adalah: (a) Pegawai yang digunakan sebagai informan dalam penelitian ini minimal telah bertugas lebih dari 1 (satu) tahun, dengan asumsi ketika telah bekerja lebih dari 1 tahun maka informan telah sangat memahami dan mengetahui tentang pengendalian yang diterapkan organisasi; (b) Informan adalah pegawai tetap (Pegawai Negeri Sipil) bukan pegawai honorer. Teknik analisis data yang digunakan dalam penelitian ini menggunakan analisis isi. ${ }^{14}$

\section{HASIL DAN PEMBAHASAN}

Informan utama berusia antara 51-57 tahun dengan jenjang pendidikan yang terdiri dari 1 (satu) S2-Kesehatan Masyarakat, 1 (satu) DIII-Keperawatan dan 1 (satu) orang S2-Kesehatan Lingkungan. Sedangkan usia informan triangulasi antara 28-54 tahun dengan jenjang pendidikan yang terdiri dari 1 (satu) SMA, 1 (satu) S1Keperawatan, dan 1 (satu) S1- Kedokteran.

Berdasarkan pada hasil analisa peneliti terrhadap hasil wawancara mendalam yang dilakukan dengan para informan, maka peneliti membagi proses analisis ke dalam 5 (lima) tema pembahasan yaitu sistem perencanaan, sistem operasional, sistem pengukuran dan penilaian kinerja, sistem umpan balik, dan sistem evaluasi dan penghargaan.

\section{Sistem Perencanaan}

Sistem perencanaan yang mencakup proses penetapan tujuan dan standar kinerja, penyusunan dan penetapan program dan anggaran menjadi salah satu mekanisme pengendalian dalam mengarahkan dan memotivasi pegawai UP4 dalam memberikan kinerja yang terbaik dalam aktivitas pelayanan kesehatan di UP4. Fakta di lapangan menunjukkan bahwa sistem perencanaan sebagai bentuk mekanisme pengendalian telah dijalankan sesuai dengan prosedur dan aturan yang berlaku. Namun demikian untuk aspek partisipasi pegawai melalui proses komunikasi dan diskusi dalam proses perencanaan harus terus ditingkatkan karena ditemukan masih belum maksimal. Padahal partisipasi merupakan salah satu aspek penting di 
dalam perencanaan sebagai sebuah mekanisme pengendalian organisasi.

Penelitian ini menemukan bahwa proses diskusi atau dialog rutin yang terformalisasi ternyata penting untuk memotivasi para pegawai. Selain itu juga diskusi atau dialog informal juga menjadi aspek yang penting untuk meotivasi dan menciptakan kondisi kerja yang kondusif, baik diskusi atau dialog antara pegawai mapuan antara pegawai dengan pihak manajemen (kepala UP4 dan kepala bagian maupun kepala seksi). Melalui diskusi atau dialog informal banyak hal penting dibicarakan termasuk penyelesaian masalah yang terjadi, sehingga hal ini dianggap oleh para informan dapat menciptakan suasana kerja yang baik dan memunculkan terobosan-terobosan baru dalam proses peningkatan kualitas pelayanan kesehatan di UP4. Oleh karena itu peneliti merekomendasikan agar diskusi atau dialog informal dapat difasilitasi oleh pihak manajemen UP4 agar intensitas-nya semakin sering terjadi. Hal ini menunukkan bahwa aspek pasrtisipasi dan komunikasi dapat dikembangkan menjadi salah satu strategi untuk mengembangkan pegawai terutama dalam meningkatkan efektifitas kerja pegawai seperti melalui diskusi atau dialog formal dan informal.

\section{Sistem Operasional}

Sistem operasional sebagai mekanisme pengendalian di UP4 yang mencakup yang mencakup SOP, dan pemberdayaan pegawai telah mampu menjadi alat pengendalian yang efektif dalam memotivasi dan mengarahkan para pegawai untuk bekerja sesuai dengan apa yang diharapkan UP4 untuk memberikan pelayanan kesehatan yang baik bagi masyarakat. Fakta di lapangan menunjukkan para informan menyatakan bahwa SOP dan pemberdayaan pegawai memberikan dampak positif dalam meningkatkan kinerja para pegawai. Hanya saja ada beberapa permasalahan yang terjadi yang diungkapkan oleh beberapa informan bahwa SOP telah dimiliki tetapi uraian tugas masing-masing individu tidak disosialisasikan dan tidak dibuat secara tertulis. Padahal hal ini merupakan sebuah kesatuan yang perlu untuk diperhatikan. Selain itu juga pemberdayaan dirasakan oleh beberapa informan tidak terjadi secara menyeluruh untuk seluruh pegawai, misalnya dalam mengikuti pelatihan hanya beberapa pegawai saja, oleh karena itu dianggap perlu bahwa UP4 memiliki program pelatihan khusus untuk internal UP4 sehingga pengalaman pemberdayaan dapat dirasakan oleh seluruh pegawai. Oleh karena itu peneliti merekomendasikan perlunya dibuat uraia tugas secara tertulis dan disosialisasikan kepada seluruh pegawai serta dibuatnya program pemberdayaan dalam bentuk pelatihan kepada seluruh pegawai.

\section{Sistem Pengukuran dan Penilaian Kinerja}

Sistem Pengukuran dan Penilaian kinerja yang saat ini diterapkan di UP4 menggunakan pendekatan "Top Down" karena mengacu pada aturan formal pemerintah yang berkaitan dengan pengukuran kinerja organisasi berdasarkan input (masukan), ouput (keluaran), oucomes (hasil), benefit (manfaat), dan impact (dampak) dan penilaian kinerja pegawai dalam bentuk SKP. Hasil analisis dari data di lapangan menunjukkan bahwa Hasil kajian dari lapangan menunjukkan bahwa para informan merasa bahwa pengukuran kinerja yang diterapkan masih jauh dari yang diharapkan, mereka menyatakan bahwa sistem penggukuran kinerja yang ada belum terbangun dengan baik sehingga pengukuran kinerja pada tingkat manfaat dan dampak terhadap masyarakat belum dapat teukur dengan baik. Para informan juga mengungkapkan bahwa penilaian kinerja pegawai dianggap kurang objektif karena berdasarkan pada subjektifitas penilaian pimpinan sehingga sering menimbulkan ketidakpuasan dikalangan pegawai. Hal ini terjadi karena UP4 belum memiliki sistem pengukuran dan peniliaan kinerja yang baik. Peneliti melihat bahwa 
UP4 memerlukan sebuah sistem pengukuran kinerja yang komprehensif (misalnya dengan mengadopsi model balanced scoredcard) sehingga dapat mengukur kinerja organisasi secara tepat dan informasi yang dihasilkan dapat menjadi masukan untuk peningkatak kualitas pelayanan. Selain itu juga dalam penilaian kinerja pegawai, walaupun sudah ada SKP sebagai standar formal pemerintah dalam penilaian kinerja pegawai, tetapi perlu juga ada sebuah proses yang dilakukan juga dengan pendekatan "bottom up" sehingga proses formulasi penilaian kinerja melibatkan para pegawai tidak hanya unsur pimpinan. Dengan partisipasi dari pegawai maka diharapkan objektifitas pengukuran kinerja pegawai menjadi lebih dipercaya sehingga menimbulkan rasa kepuasan dan dapat memotivasi pegawai untuk bekerja lebih optimal dalam memberikan pelayanan kesehatan bagi masyarakat.

\section{Sistem Umpan Balik}

Umpan balik menjadi salah satu alat pengendalian yang cukup efektif di UP4 untuk mengarahkan perilaku para pegawai dalam menciptakan perbaikan kinerja melalui informasi yang diberikan. Umpan balik dinyatakan sebagai oleh para informan dapat memberikan pemahaman terhadap anggota organisasi karena terdiri dari informasi yang relevan dengan kondisi kerja nyata diapangan sehingga mampu menjadi alat pengendalian manajemen untuk memotivasi dan mengarahan pegawai untuk meningkatkan kinerja pelayanan kesehatan di UP4. Para informan menekankan tentang pentingnya aspek ketepatan waktu dan juga akurasi informasi yang berkaitan dengan objektifitas penilaiaan terhadap tingkat keberhasilan dan kegagalan pelaksanaan tugas di lapangan. Oleh karena itu peneliti merekomendasikan agar aspek ini menjadi perhatian penting bagi pihak manajemen UP4 untuk segera dilaksanakan untuk semakin mengefektifkan sistem umpan balik yang dimiliki UP4.

\section{Sistem Evaluasi dan Penghargaan}

Sistem evaluasi dan penghargaan yang dilakukan oleh pihak UP4 dilaksanakan oleh pihak manajemen UP4 berdasarkan penilaian subjektif berdasarkan kisaran hasil kerja yang dicapai oleh para pegawai. Sistem evaluasi dianggap masih sangat lemah dan tidak efektif oleh sebagian informan dalam mengarahkan dan memotivasi peningkatan kinerja pelayanan kesehatan. Hal ini berkaitan dengan relevansi, keakuratan, dan ketepatan waktu informasi yang digunakan sebagai dasar evaluasi. Oleh karena itu meneliti menekankan pentingnya untuk UP4 memili suatu sistem pengukuran kinerja yang komprehensif karena sistem pengukuran kinerja yang komprehensif akan menghasilkan informasi yang akurat, tepat waktu, relevan dan lengkap yang dibutuhkan untuk melakukan evaluasi kinerja individu maupun organisasi secara keseluruhan. Sedangkan untuk sistem penghargaan, para informan menyatakan di UP4 belum memiliki sistem penghargaan yang terformalisasi secara baik. padahal menurut para informan pemberian penghargaan secara sangat penting sabagai alat pengendalian manajemen dalam meningkatkan motivasi anggota organisasi untuk memberikan pelayanan kesehatan yang maksimal. Memang sangat disadari bahwa di dalam lingkungan organisasi pemerintah mekanisme pemberian penghargaan dalam bentuk reward dalambentuk finansial tidaklah ada tetapi hanya dalam bentuk pemberian satya lencana sebagai bentuk penghargaan terhadap pengabdian dan juga melalui penghargaan secara verbal. Peneliti merekomendasikan agar pihak UP4 memformalisasikan sistem penghargaan di UP4 agar dapat menjadi alat pengendalian untuk memotivasi kinerja anggota organisasi. Sistem penghargaan dapat didesain dalam bentuk kegiatan-kegiatan capacity building yang diadakan sebagai bentuk penghargaan dan apresiasi terhadap kinerja yang telah dicapai. 


\section{KESIMPULAN}

Hasil penelitian ini menunjukkan bahwa SPM belum dilaksanakan secara baik di UP4. Pihak manajemen UP4 perlu untuk melakukan beberapa perbaikan dan peningkatan dalam desain dan penerapan SPM di UP4. Aspek partisipasi anggota dan komunikasi merupakan salah satu aspek penting yang harus diperhatikan dalam melakukan pengendalian di UP4. Pihak UP4 juga perlu untuk mendesain sistem pengukuran kinerja yang komprehensif. Selain itu mekanisme evaluasi dan penghargaan juga perlu diformalisasikan secara baik.

\section{UCAPAN TERMA KASIH}

Penulis menyampaikan terima kasih yang sebesar besarnya kepada pimpinan dan staf UP4 Kalimantan Barat yang telah bersedia meluangkan waktu menjadi informan pada penelitian ini.

\section{DAFTAR PUSTAKA}

1. Republik Indonesia. Surat Keputusan Menteri Kesehatan Republik Indanesia Nomor 129/Menkes/SK/II/08 tentang Standar Pelayanan Minimum Rumah sakit. Kementrian Kesehatan. Jakarta. 2008

2. Republik Indonesia. Undang-Undang Nomor 32 tahun 2004 tentang Pemerintah Daerah. Jakarta. 2004

3. Flamholtz, E. G. Effective Organizational Control: A Framework, Applications, and Implications. European Management Journal. 1996; Vol. 14; No. 6; 596-611

4. Republik Indonesia. Peraturan Pemerintah Republik Indonesia No. 60 Tahun 2008 tentang Sistem pengendalian intern pemerintah (SPIP). Jakarta. 2008

5. Bastian, Indra. Sistem Pengendalian Manajemen Sektor Publik. Salemba Empat: Jakarta. 2013
6. Flamholtz, E. G., Das, T. K., and Tsul, A. Toward an Integrative Framework of Organizational Control. Accounting, Organizations and Society. 1985; Vol. 8; No. 1; 35-50.

7. Unit Pengobatan Penyakit Paru-Paru. Laporan Kinerja Tahunan Pemerintah Tahun 2015. Pontianak. 2015

8. Santosa, H. Persepsi Masyarakat Terhadap Kualitas Pelayanan Kesehatan Di Puskesmas Binjai Kota. Universitas Sumatra Utara. 2007

9. Andriani, S., dan Sunarto. Hubungan Kualitas Pelayanan Kesehatan Dengan Kepuasan Pasien Rawat Inap Di Badan Pelayanan Kesehatan Rumah Sakit Umum Daerah Kabupaten Magelang. Jurnal Kesehatan. 2009; Vol.2; No.1; 71-79

10. Apriyanto, H. R, Kuntjoro, T., dan Lazuardi, L. Implementasi Kebijakan Subsidi Pelayanan Kesehatan Dasar Terhadap Kualitas Pelayanan Puskesmas Di Kota Singkawang. Jurnal Kebijakan Kesehatan Indonesia. 2013; Vol. 2; No. 4; 180188.

11. Konli, S. Pelayanan Kesehatan Masyarakat Di Puskesmas Desa Gunawan Kecamatan Sesayap Kabupaten Tana Tidung. eJounal Ilmu Pemerintahan. 2014; Vol. 2; No. 1; 1925-1936

12. Fazrin, N. Kualitas Pelayanan Kesehatan Di Puskesmas Segedong Kecaatan Segedong Kabupaten Mempawah. Jurnal S-1 Ilmu Administrasi Negara 2015; Vol. 4; No.2

13. Creswell, J. W. Research Design: Pendekatan Metode Kualitatif, Kuantitatif, Dan Campuran. Edisi Keempat, Penerbit Pustaka Pelajar, Yogyakarta. 2016

14. Creswell, J. W. Penelitian Kualitatif dan Desain Riset. Edisi Ketiga, 
Penerbit Pustaka Pelajar, Yogyakarta.

2015 